\title{
The research on the preferences of public building owners for energy saving incentive policy instruments
}

\author{
Erxin $\mathrm{ZHANG}^{1, a}$, Jianglong MIAO ${ }^{2, b}$ \\ ${ }^{1}$ School of Xi'an University of Architecture and Technology, Xi'an 710055, China \\ ${ }^{2}$ School of Beijing Jiaotong University, Beijing100044, China \\ ${ }^{a}$ m15202414676@163.com ,b14121064@bjtu.edu.cn
}

Keywords: Public building owner; Incentive policy instruments; Preferences; Influencing factors

\begin{abstract}
The preference of public building owners to the energy saving incentive Instruments of building determines the influence of policy tools, which is formulated and implemented by the government.In this paper,firstly we defines the types of building energy-saving incentive policies,and identify the influence factors of public building owners to incentive policy tools.Secondly, we analyzes the characteristics of the factors affecting the policy preferences of the public buildings, the preference of the public building owners to those policy tools and the relationship between them.Finally, in order to improve the energy efficiency of public buildings,the paper puts forward some policy suggestions for the government.
\end{abstract}

\section{Introduction}

In recent years, with the rapid economic development, China's total energy consumption is growing rapidly year by year. China's building energy consumption accounts for $33 \%$ of the total social energy consumption, and the average per unit area energy consumption of public buildings is two or three times as much as other buildings ${ }^{[1]}$. Therefore, it is the fundamental way to realize the goal of saving energy by transforming the energy saving potential into the internal driving force of energy saving behavior under the guidance of the policy.

Compared with other buildings, public buildings have more demonstration effect and social influence. Therefore, it is imperative to solve the high energy consumption of public buildings. The research results show that the incentive mechanism is an effective way to solve this problem. According to the different functions, this paper divides the public buildings into four types: government office buildings, medical buildings, shopping malls, hotel buildings. The existing incentive policy is not significant ${ }^{[2]}$. Shuai Gao finds that the owners' preferences for a variety of domestic policies determine the success of energy efficiency incentives or not. However,most research on the incentive policy tools of public buildings is based on the theoretical level, so they don't provide enough support in practice. Therefore,this paper pay attention to the preference of public building owners to incentive policy instruments from the perspective of the practice, basing on the motivation to stimulate the enthusiasm of the owners.

\section{Literature review and model building}

\subsection{Types of building energy-saving policy tools}

The incentive policy tools have different effects on the target groups, so different types of public building owners may have different preferences for the same incentive policy tools ${ }^{[3]}$. Many domestic and foreign scholars have carried out a study on the energy saving incentive policies. In this paper, the author sorts out the classification of building energy efficiency incentive policies, as shown in table 1. 
Table 1 Types of incentive policy instruments

\begin{tabular}{|c|c|c|}
\hline Seq- number & Scholars & Types of incentive policy instruments \\
\hline 1 & $\begin{array}{c}\text { Nan } \\
\text { Zhou,Mark } \\
\text { D.levine }^{[4]}\end{array}$ & $\begin{array}{l}\text { Energy regulation, economics, information services, education and training } \\
\text { and advocacy, research and demonstration }\end{array}$ \\
\hline 2 & $\begin{array}{l}\text { Beijia } \\
\text { Huang }^{[5]}\end{array}$ & Mandatory, economic, financial support, information support \\
\hline 3 & $\begin{array}{l}\text { Stephen } \\
\text { wiela }^{[6]}\end{array}$ & Energy regulation, voluntary agreement, economy \\
\hline 4 & $\begin{array}{l}\text { Liyin } \\
\text { shen }^{[7]}\end{array}$ & Energy regulation, economy, voluntary targets \\
\hline 5 & Marilyn $^{[8]}$ & New technology research and development, voluntary goal \\
\hline 6 & $\begin{array}{l}\text { Jia Chang } \\
\operatorname{Lin}^{[9]}\end{array}$ & $\begin{array}{l}\text { According to the characteristics of China's government agencies, he put } \\
\text { forward the performance evaluation of energy-saving incentive policy tools }\end{array}$ \\
\hline
\end{tabular}

Economic incentive policy instruments include financial subsidies,preferential tax policy ${ }^{[5][6][7]}$.Many scholars like Stephen wiela believe that the voluntary agreement incentive policy tools can make the public building owners take the initiative to save energy, because they can get spillover benefits.The voluntary agreement incentive policy instruments include two specific policies: the selection of "Energy Star" enterprises, energy consumption trading policy ${ }^{[7][8][9]}$.By investigating the characteristics of the financial system of China, Chang put forward the performance appraisal incentive policy tools, which putting the energy-saving effect into the performance appraisal content, in order to encourage the person liable to actively energy-saving.

Table 2 The types of public building energy saving incentives policy tools

\begin{tabular}{ccc}
\hline $\begin{array}{c}\text { Types of incentive policy } \\
\text { tools }\end{array}$ & Policy description & Code \\
\hline \multirow{2}{*}{$\begin{array}{c}\text { Energy regulatory incentives } \\
\text { policy tools }\end{array}$} & $\begin{array}{c}\text { setting building energy consumption quota } \\
\text { setting building energy conservation regulations }\end{array}$ & $\mathrm{Y}_{1}$ \\
& system of rise the price if over quota & $\mathrm{Y}_{2}$ \\
\hline Economic incentive policy & Financial subsidy policy & $\mathrm{Y}_{4}$ \\
tools & Preferential tax policy & $\mathrm{Y}_{5}$ \\
\hline Voluntary target incentive & Appraise and elect'energy Star Enterprise' & $\mathrm{Y}_{6}$ \\
policy tools & Energy consumption trading policy & $\mathrm{Y}_{7}$ \\
\hline Performance appraisal & Implement energy performance appraisal policy & $\mathrm{Y}_{8}$ \\
incentive policy tool & &
\end{tabular}

In order to stimulate the enthusiasm of public buildings in China,we combine the universally recognized energy efficiency incentive policies with China's fiscal system. We divided the policy tools into four categories,As shown in table 2:

\subsection{Influencing factors of the policy preference instruments}

The evaluation of the public building owners to the policy effects will greatly influence the preference of the owners to the energy conservation policy instruments. We researched the Influencing factors of the policy preference instruments,this paper divides the factors into three parts; internal factors, external factors and control factors.

\subsubsection{External determinants}

Many scholars try to explain the company's environmental behavior through organizational 
theory.From the perspective of organization theory, it is considered that the external pressure greatly influences the evaluation of the effect of the policy.

On the one hand, due to the nature of the enterprise which possess public buildings is an economic organization, they rarely pay attention to the sustainable development of the industry and the environment. Therefore, the pressure from the society, government and the market to the enterprise has become the driving force for the energy saving of public building owners. On the other hand, the public building owners who save energy and reduce emission , consumers actively will shape the brand image and enhance social image.When the public building owners found that the violation of government regulations will bring losses, but in response to the implementation of government incentives to bring benefits, the public building owners will be forced to accept the energy regulatory system and policies.As time goes by, they will constantly adjust themselves to form a new understanding and action orientation ${ }^{[10]}$.Through the above analysis, this paper divides the external factors into two points: government pressure and social expectation.

\subsubsection{Internal determinants}

However, organizational perspective is not always effective, usually the owners who are beared same external pressure has different preferences to public building energy efficiency policy tools. Delmas demonstrates that this is because each company has its own characteristics,so the pressure they feel and preferences for policies is also different.Through the research, it is found that the internal characteristics can be divided into three categories. (1)learning ability.Learning ability reflects the ability of the owners to collect domestic policy information ${ }^{[11]}$. (2)Energy-saving potential.The high energy saving potential makes the public building owners have more flexibility to the energy conservation policy.So they will form the inherent driving force of energy saving and emission reduction ${ }^{[12]}$.3)Status of energy management in public buildings. The more the owners know about their own energy use and emissions, the more likely to accept policies based on energy efficiency goals.Therefore, the internal factors that affect the energy efficiency policy tools of public building owners can be divided into three parts: learning ability, energy saving potential, energy management status.

\subsubsection{Control determinants}

Through the related research,it is found that the large enterprises is more easily controlled by government. In the process of improving energy efficiency, large energy consuming enterprises are the focus of the government ${ }^{[13]}$.Some scholars have confirmed that small-scale enterprises is in disadvantages in the collection information of energy-saving .Therefore,combined with the characteristics of public buildings in China, we take the scale of enterprises as a control determinants for public building energy efficiency policy preferences.

\subsection{Model building}

Through the above analysis, this paper defines the types of incentive policies and the factors which affect the owners' preference, and each incentive policy tool contains specific incentive policies.Through the questionnaire, we analyzes the influence factor and the preference of each owner to the policies. In the end,we get the owner's preference for different incentive policies.Through the use of multiple linear regression analysis, we analyze the impact of internal factors, external factors and control factors on the owners' preferences. Then we explains why the different preferences of different types of public building owners to different incentive policies scientifically.The research model is as follows. 


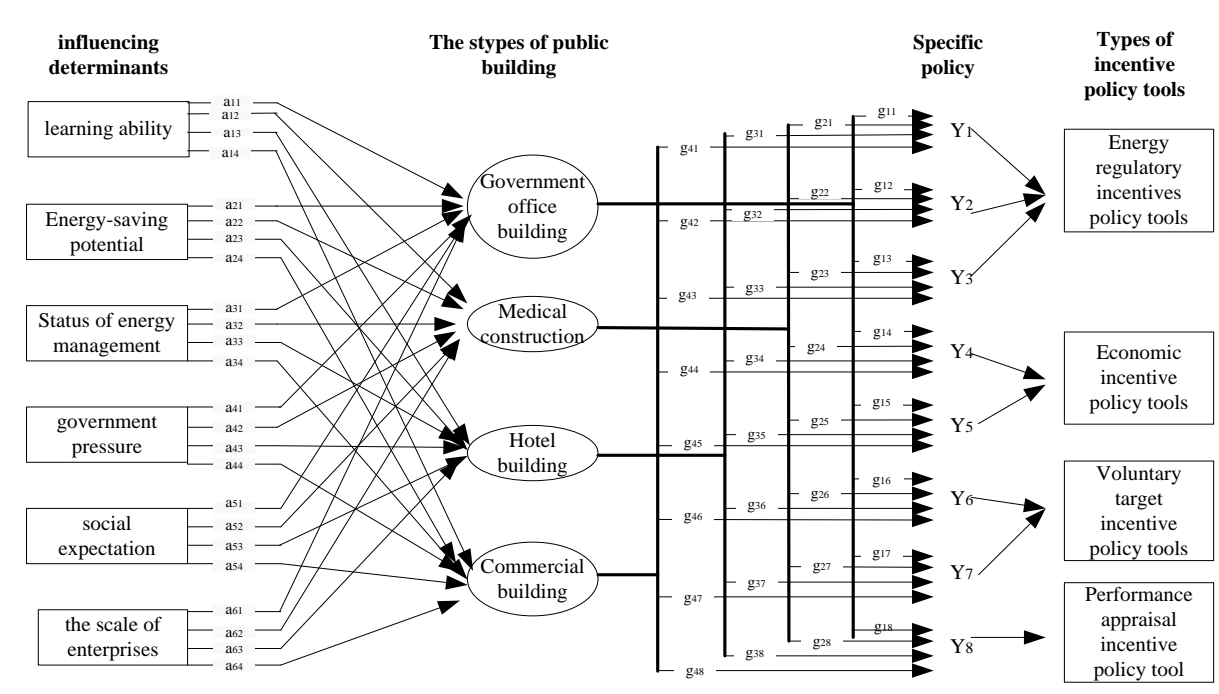

Figure 1 Conceptual model

\section{Research design}

\section{1 survey design}

The questionnaire is divided into three parts. (1)The company's basic situation, including the scale of the company and the education level of company staff. (2)Internal factors,external factors and control factors of public buildings, which is used to figure out the reasons why public building owners have different preference to the policy. (3) Owners' preferences for energy policy.

\subsection{Analytical methods}

Through the above analysis, the formal questionnaire including 24 questions is formed. The survey object are public building owners and some of the heads of the public. The analysis of the data is divided into two steps.Firstly,through a simple quantitative analysis, we can obtain that the significant level of the internal factors in public buildings and various types of public building owners' preference level to specific policies.Secondly, we perform a regression analysis to examine if the determinants identified in the analytical framework are related to the company's preferences for the different policies. Dependent variable is preference level,and the independent variable is influence factor.The following is the calculation model of multiple linear regression analysis:

Policy pre : $\mathrm{Gi}=\beta_{\mathrm{i}}+\beta_{1} * \mathrm{X}_{1}+\beta_{\mathrm{i} 2} * \mathrm{X}_{2}+\beta_{\mathrm{i} 3} * \mathrm{X}_{3}+\beta_{\mathrm{i} 4} * \mathrm{X}_{4}+\beta_{\mathrm{i} 5} * \mathrm{X}_{5}+\beta_{\mathrm{i} 6} * \mathrm{X}_{6}$

The dependent variables in Eq.(1) are rated on an ordinal,five-point Likert scale. $X_{1}$ stands for learning ability; $\mathrm{X}_{2}$ stands for energy-saving potential; $\mathrm{X}_{3}$ stands for the status of enterprise energy management; $X_{4}$ stands for government pressure; $X_{5}$ stands for the expectations of relevant groups; X6 said the size of enterprises. $\mathrm{I}=1,2, \ldots 8, \mathrm{G}$ i represents the owner's preference for eight specific incentive policies.

\section{Results}

Questionnaires were distributed by e-mail and paper.145 questionnaires were release but 129 were collected. And then 21 invalid questionnaires were removed from them. 108 valid questionnaires were obtained in the end. By summarizing the data, we got three conclusions: the internal and external factors of various types of public buildings enterprises, the preference of the public building owners, and the relationship between them.

\subsection{Statistical summary of the determinants}

The survey results show that the internal and external factors of different types of public buildings are quite different.The government office buildings have significant learning ability and policy pressure; The medical buildings have significant learning ability, energy saving potential and enterprise scale characteristics; The hotel buildings have significant energy saving potential and enterprise scale characteristics; Shopping malls buildings have significant energy saving potential, 
social expectations characteristics. All above lead to different preferences for incentive policy tools.

\subsection{Public building owners' preferences for various energy-saving policy instruments}

The survey also shows the preferences of different types of public building owners for different energy policy instruments. According to the survey results, government building owners prefer energy regulatory policy tools and performance appraisal policy (Y1, Y2, Y8). The medical construction owners prefer the energy regulatory policy tools and economic incentive policy tools (Y1, Y2, Y4, Y5).And the hotel building owners prefer economic incentive policy tools (Y4, Y5). The mall building owners prefer the economic incentive policy tool and the Voluntary target incentive policy tool (Y4, Y5, Y6). The hotel building owners prefer the economic incentive policy tool (Y4, Y5). It can be seen that different types of public building owners have different preferences for different policy instruments, which is directly related to the internal and external factors of the public buildings owners themselves.

\subsection{Relationship between policy preferences and determinants}

An mult-variable linear return analysis is used in order to identify potential determinants of policy preferences. The regression results are presented in table 3 . We can find that the preference character of $\mathrm{Y} 1$ and $\mathrm{Y} 2, \mathrm{Y} 4$ and $\mathrm{Y} 5, \mathrm{Y} 6$ and $\mathrm{Y} 8$ are respectively similar.It can be seen that the preference for Y1 is related to the learning ability of employees, the government pressure and the level of enterprise energy management. The stronger of them the more prefer of the owners for Y1; The preferences for Y3 has a greater relationship with governmental pressure, the business beard and the corporate energy management level; The preference for $\mathrm{Y} 4$ has a greater relationship with energy-saving potential and the scale of enterprises.The above factors all were positively correlated with preferences for Y4. The greater of government pressure and the social expectation lead to greater preference for Y6;The preference for Y7 has a great relationship with government pressure, the status of enterprise energy management and the scale of enterprises .

\section{Results and discussion}

The results show that the influencing factor and the preferences are related very closely.Public building owners of different types show different preferences for incentive policy tools.

1) Government office building owners preference energy regulation and energy performance appraisal incentive policy tools.Firstly,Government office building owners need to act in accordance the regulations, bearing greater government pressure, so the owners show more preference for energy regulatory incentives policy tools. Secondly, the people in charge most concerned the "performance".So establish energy efficiency assessment mechanism, connecting the energy conservation with the promotion of the charge men together will improve the energy efficiency .So these owners prefer energy performance appraisal incentive policy tools.

Table 3 Relationship between policy preferences and determinants

\begin{tabular}{|c|c|c|c|c|c|c|c|c|c|}
\hline \multirow{2}{*}{\multicolumn{2}{|c|}{$\begin{array}{c}\text { Independent } \\
\text { variable } \\
\end{array}$}} & \multicolumn{8}{|c|}{ Dependent variable: policy preferences } \\
\hline & & \multirow{2}{*}{$\frac{G_{1}}{0.331}$} & \multirow{2}{*}{$\frac{\mathrm{G}_{2}}{0.402}$} & \multirow{2}{*}{$\frac{G_{3}}{-0.171}$} & \multirow{2}{*}{$\frac{\mathrm{G}_{4}}{0.016}$} & \multirow{2}{*}{$\frac{G_{5}}{-0.150}$} & \multirow{2}{*}{$\frac{\mathrm{G}_{6}}{0.065}$} & \multirow{2}{*}{$\frac{G_{7}}{-0.029}$} & \multirow{2}{*}{$\frac{G_{8}}{-0.259}$} \\
\hline & Lea & & & & & & & & \\
\hline \multirow{2}{*}{$\begin{array}{l}\text { Internal } \\
\text { factors }\end{array}$} & pot & -0.251 & -0.318 & -0.074 & 0.034 & 0.190 & 0.043 & 0.076 & 0.058 \\
\hline & $\operatorname{man}$ & 0.473 & 0.002 & 0.179 & -0.174 & -0.379 & -0.266 & 0.125 & 0.1088 \\
\hline \multirow{2}{*}{$\begin{array}{c}\text { External } \\
\text { factors }\end{array}$} & pre & 0.289 & 0.264 & 0.177 & -0.226 & -0.306 & 0.162 & -0.345 & 0.387 \\
\hline & Soc & 0.031 & 0.032 & -0.107 & 0.006 & 0.086 & 0.248 & -0.098 & 0.352 \\
\hline $\begin{array}{l}\text { Control } \\
\text { factors }\end{array}$ & scale & -0.036 & -0.079 & 0.074 & 0.3240 & 0.299 & 0.0903 & 0.176 & -0.338 \\
\hline \multicolumn{2}{|c|}{$\mathrm{N}$} & 108 & 108 & 108 & 108 & 108 & 108 & 108 & 108 \\
\hline \multicolumn{2}{|c|}{ Confidence level } & 0.05 & 0.05 & 0.05 & 0.05 & 0.05 & 0.05 & 0.05 & 0.05 \\
\hline \multicolumn{2}{|c|}{ Residual } & 0.463 & 0.426 & 0.073 & 0.369 & 0.452 & 0.186 & 0.284 & 0.408 \\
\hline
\end{tabular}

2) Medical building owners prefer economic and energy regulatory incentive policy 
tools.Firstly,the area of medical buildings is usually above $20000 \mathrm{~m}^{2}$, the energy saving space is larger.These buildings have a greater potential to save energy costs, so medical construction owners show preference for economic incentives policy tools.Secondly, the relevant person in charge of the medical construction shows higher learning ability to participate in such measures quickly to save energy costs.So the owners show preferences for energy monitoring incentive policy tool.

3)Hotel building owners prefer economic incentive policy tools.Hotel building have a large energy consumption, energy-saving potential, resulting in high energy costs, and construction costs bear by their own.Hotel is a for-profit organization, in order to meet customer requirements for comfort, will ignore the performance appraisal policy tool.The implement of financial subsidies and loan discounts can be a good incentive for such buildings to carry out energy conservation and emission reduction. Therefore, the owners show preference for the economic incentive policy tool.

4)Shopping mall owners prefer economic incentive voluntary target incentive policy tools.commercial malls have a high social expectations and they concern about their own interests and recognition of customers about the business. Scholars found that consumers prefer to buy green products. Selection of "Energy Star" enterprises can reflected the information which the enterprises invest in energy-saving to customers, the recognition of customers will become the energy-saving investment driving force. So the owners show preference for voluntary target incentive policy tool.

\section{Conclusions and recommendations}

Public buildings as an important consumer of energy products in China, its energy conservation is of great significance. There are many types of public buildings in our country. Their internal and external factors which determine the nature of public buildings are different.Therefore, the preferences of owners for various incentive policy tools are also different. Based on the results of this study, we made the following recommendations:

1) The different types of public building owners show different preferences for the incentive policy tool,so the government should give full consideration to owners' demands,so thhat they can develop more targeted policies for Various types of buildings.

2) There are sever recommendations for government to set policies:For the government office building owners,government should strengthen energy regulation and energy performance appraisal incentive policy tools;For medical buildings owners,government should strengthen economic and energy monitoring policy instruments;For Hotel building owners,government should strengthen economic policy tools ;For commercial building owners,government should strengthen economic policy instruments and voluntary target policy tool incentives.

\section{References}

[1] Liu Huabing.Research on Incentive Policy for Energy Efficiency Reconstruction in Large Public Buildings [D].Chongqing: Chongqing University, 2012.

[2] LI, JUN. A comprehensive analysis of building energy efficiency policies in China: status quo and development perspective [J]. Journal of Cleaner Production,2015，90(1): 326- 344.

[3] Cao Xiao Juan,Li He Zhong.The Decision Model Analysis to Incentive Policy for Low- Carbon Economic Development for Resource -saving and Environment -friendly Society[J]. China Soft Science, 2011, 7:66-73.

[4] Nan Zhou , Mark D. Levine, Lynn Price. Overview of current energy-efficiency policies in China[J].Energy Policy,2015, 38(2010):6439-6452.

[5] Beijia Huang a, Volker Mauerhofer, Yong Geng .Analysis of existing building energy saving policies in Japan and China[J] . Journal of Cleaner Production,2015,8,1-9.

[6] Stephen Wiela,Nathan Martina,Mark Levineb, Lynn Pricea, Jayant Sathayea,The role of 
building energy efficiency in managing atmospheric carbon dioxide[J] .Environmental Science \& Policy, 1998, 1, 27-38.

[7] liyin shen,Bei He,Liudan jiao,Research on the development of main policy instruments for improving building energy-efficiency[J] . Journal of Cleaner Production,2015,7,1-15.

[8] Marilyn A Brown,Market failures and barriers as a basis for clean energy policies[J] . Energy Policy,2001,29,1197-1207.

[9] JIA Chang-lin, Two Incentive Models for Energy Efficiency in Public Buildings[J],Building Energy EFFICIENCY, 2014, 6, 104-106.

[10] Dai Xuezhi, Wu Yong,Government regulation and its innovation for large-scale public building energy efficiency supervision systems under market economy[J],Heating Ventilating \& Air Conditioning, 2007,8,2-7.

[11] Hart, S.L.. A natural-resource-based view of the firm. Acad. Manag[J]. Rev. 1995.20 (4),986-1014.

[12] Sunhee suk, xiaobing liu, Affordability of energy cost increases for Korean companies due to market-based climate policies: a survey study by sector [J]. Journal of Cleaner Production,2014,67, 208-219.

[13] Zhang, Z.X.. China in the transition to a low-carbon economy. Energy Policy[J].2010.38, 6638-6653. 